\title{
LABORATORY EXERCISE OR LECTURE: MIDDLE SCHOOL EDUCATION
}

\author{
Barry R. Thompson, PhD \\ Georgia Regents University, U.S.A.
}

\begin{abstract}
A study was recently conducted in a suburban middle school regarding two teaching strategies. Ninety-three eighth grade students were administered a pretest regarding classification as related to taxonomy. Thirty of the students conducted an inquiry lab concerning classification. They then participated in a class discussion regarding the material. The remaining thirty students first participated in a class discussion regarding classification, they then completed the laboratory exercise. A posttest was administered at the conclusion of the unit and a retention test was administered four months later. Statistical analysis through the use of t-tests indicates a statistically significant performance difference on the scores of the posttest. No significant difference was found when comparing the respective retention test scores.
\end{abstract}

Keywords: Inquiry, laboratory, taxonomy

\section{Introduction} Classes?

Laboratory Exercise or Lecture: What Should Come First in Science

How one learns best is a universal question which many have devoted their research lives to solving. Pedagogy is often taught with the idea that students have various learning styles such as auditory, visual, etc. (Dunn, et.al., 1995). Instructional variety in the classroom will help to address the various ways students learn such as the use of hands-on activities balanced with class discussions in order to best address the respective learning styles of their students in conjunction with preparing the students for evaluation. Standardized tests have become the evaluation procedure of choice with the advent of national and state standards therefore, teachers have the obligation to instruct in a manner that best results in increased learning by their students as measured by standardized tests.

In addition to learning styles, theories such as the use of inquiry in the classroom increased greatly during the decade of the 1960's thanks in 
part to the launch of Sputnik, which caused a great deal of curricular concern in the United States. New science curricula were designed that stressed inquiry and process, using hands-on laboratory experiences as a means to facilitate learning. The resulting standardized test scores related to these curricula were analyzed in the 1980's comparing the results of students who had participated in the proper use of the inquiry science curricula (Shymansky, Kyle, \& Alport, 1982; Shymansky, 1984). The achievement test scores of those original students increased and attitudes became more positive. Several of these programs (Science Curriculum Improvement Study, Science A Process Approach, Biological Science Curriculum Study) were successful in using the process approach in order to increase learning for a variety of age groups.

Further research results have indicated conflicting outcomes regarding pedagogical techniques. Odubunmi, Olagunqu and Balogun (1991) found that when comparing the lecture versus laboratory teaching method, the cognitive achievement scores of low ability students were significantly higher for pupils instructed using the laboratory activities. There was, however, no significant difference in test scores when comparing high ability students and teaching method. In another study, Staver (1984) tested traditional teaching-vs-inquiry based learning. This researcher concluded that the methods of teaching had no significant impact on students' test scores.

Calude, C., Calude, E., \& Queen, M. (2012). Inductive Complexity of $\mathbf{P}$ versus NP Problem (Extended Abstract). Lecture Notes in Computer Science. (7445), 2-9.

Calude, C.S. ;

Calude, E. ;

Queen, M.S.

Title: Inductive Complexity of $\mathbf{P}$ versus NP Problem (Extended Abstract)

Source:

Lecture notes in computer science. no. 7445, (2012): 2-9 Additional Info: Springer-Verlag, Issue Id: Unconventional Computation and Natural Computation

Alt Journal: Key Title: Lecture notes in computer science

Standard No: ISSN: 0302-9743 CODEN: LNCSD9

OCLC No: 3719235

BL Shelfmark: 5180.185000

Article Type: Article

Database: ArticleFirst

Conversely, Saunders (1987) found that hands-on learning was more effective for student learning than was traditional lecture. It was also found 
that supplementary inquiry activities had a significant positive effect on the achievement of females, indicating an interaction between gender and teaching strategy (Marshall \& Dorward, 2000).

The study was conducted in Australia to determine whether inquiry or lecture is better for college students (Jones, Holland, \& Oldmeadow, 2008). The participants included 49 college students. The same students were exposed to both the inquiry and the lecture method and the results indicated a significant improvement with the inquiry approach at the .001 level. They also found they could cover more content using the lecture method.

Another study was done at the collegiate level regarding the correlation between attendance at laboratory experiences and grades (Moore, 2008). This was a longitudinal study lasting for years and involving 1697 students. The researcher found that the students' respective grades declined progressively as the students missed one or more labs. Studies done with collegiate level students seem to indicate benefits of hands-on experiences and inquiry learning.

Saunders (1987) conducted his research in $4^{\text {th }}$ and $6^{\text {th }}$ grade science classes. His findings indicated hands-on learning was better for student learning than traditional lecture type learning. Additionally, Chang (1999) whose participants included 600 junior high school students, found that students in the inquiry-group instruction classes had significantly higher achievement scores than the students in the traditional group instructional classes.

These researchers exposed different respective groups of students to different teaching approaches, lecture vs. lab, and lecture vs. inquiry. This creates the need for a study where the same students, as opposed to different classes of students, are taught the same material using different methods. This eliminates the potential confounding variable, different groups of students. Each classroom of pupils may react differently to various learning methods. These researchers also used achievement and gender as variables. A study now needs to be conducted whereby a common variable, such as socio-economic status can be compared to achievement.

Research also indicates that even students who scored well on standardized tests are often unable to successfully integrate or contrast memorized facts with real-life applications outside the school room (Yager, 1991). Studies on authentic assessment showed that an educational intervention based on the theory of successful intelligence improved school achievement, both on performance assessment measuring analytical, creative, and practical achievements and on conventional multiple-choice memory assessment.

Educators are beginning to acknowledge the importance of honoring the principles of authentic assessment. These principles require teachers to 
focus on approximating authentic real-world tasks in the subjects under study and on higher-order thinking skills, all while using assessment as a means for continual student improvement. This gives the student a better learning experience, and increases the chances that what they have learned will be of use to them beyond their current classroom. According to research, traditional assessment tools are often not helpful in assisting students to improve, to understand, or synthesize what they have learned (Wilson, 1994).

Findings from teacher questionnaires indicates that teachers feel that students achieve high scores in science knowledge and maintain or develop positive attitudes towards science when students are provided with opportunities that use real-world scenarios to make connections between what they learn in science class and what they do in life (Brunkhorst, 1992).

\section{Method}

The implications of the research data indicate a need for more research. Many different variables, such as socio-economic status, must be explored in order to determine what teaching procedure is preferable for any respective group of students. The population was seventh grade students in a suburban, middle to upper class environment.. The students had previously been randomly assigned to specific science classes, and the teaching strategy was randomly chosen for each class.

There were four classes randomly assigned to each condition. All four classes were taught in the same science classroom by the same teacher and included standard furniture for a lecture/lab setting. There were 26 standard-sized desks for middle school students evenly spaced throughout the room. In addition, there were lab stations for groups of four students. The materials for the laboratory exercise were spread evenly around the lab.These materials included are a variety of organisms from the animal kingdom. Examples included various lizards, shells, bones, etc., and other organic matter which represented many phyla. There is a teacher work station at the front of the room which includes a sink and a gas jet. The station was designed in order for the instructor to do a demonstration that the whole class can see. The station was therefore raised at a higher level than the student lab tables and was designed so the instructor would stand while doing a demonstration. Each teaching condition was designed to eliminate confounding variables such as a room change or change in instructor.

The teacher had previously taught several years and was working on her Masters degree. The teacher decided to incorporate both hands-on and lecture instructional procedures into the unit. She assessed content knowledge at two intervals during the experiment and compared the results. The students were assessed twice during the study. They were administered a 
pretest, and a posttest. Pretests were administered one week before the beginning of the study. The posttests were administered on the day following completion of the study. Both the prestest and the posttest were worth 100 points.

Results were calculated from the scores of 60 high school students. The students were enrolled in a sophomore biology class in an urban high school. Sixty-five percent of the participants were on free or reduced lunches. The racial status was $60 \%$ minority.

One week before the unit on classification was taught, the student teacher administered a pretest to each biology section. This test assessed their pre-knowledge of the material that would later be presented. The students were taught the process of classification through the use of a lab before the lecture for two class sections, while the lecture was presented before the lab for the other two. Following one week's worth of teaching using lecture, lab, and review, a posttest was administered that dealt with the material that had been covered in the unit. The classes' posttest scores were compared to pretest scores. The number and percent change for each individual and each class was calculated. Totals were also calculated for the classes that had undergone the same respective procedure. Furthermore, a ttest was used to determine if there was a statistically significant difference noted between the performances of the classes based on whether they had lab or lecture first.

Further assessments were conducted to evaluate the amount of content retained by the participants. Three of the four classes included in the pre and posttests were given the assessment instrument four months after the posttests were administered. These scores were then compared with the posttest scores in order to determine whether the teaching procedure impacted the amount of content retained over time.

The content addressed in this experiment involved classification and Kingdoms. The student teacher designed an inquiry laboratory experience whereby the students constructed hypotheses regarding the relationships between a collection of artifacts. The students were given such materials as lizards, shells, bones, etc., and asked to classify them and justify their decisions. The student teacher also designed a lecture/class discussion regarding the evidence concerning classification and the characteristics used for classification. Two classes designed their own classification schema, then the student teacher led a class discussion regarding the content. The student teacher conducted a lecture/class discussion first with the two remaining classes, then those classes completed the inquiry lab. All students took part in both the inquiry lab and the lecture/class discussion with the only variable being whether they had lecture first or lab first. 


\section{Results}

A t-test was run on the data in order to compare the lab first versus the lecture first teaching strategy. The two classes that were involved in a class discussion before the laboratory experience had statistically significantly higher (.05 level) posttest scores than those who were involved in an inquiry lab before the class discussions (see Table I). A t- test was also used in order to assess the results of the scores on the retention test. The class means decreased for every class resulting in no significant difference on the retention scores between the lab first and lecture first groups.

Table I. Means, Standard Deviations, and t-Value Regarding Lab First vs. Lecture First

$\begin{array}{lllll}\text { Test } & \text { Group } & \underline{\text { Mean }} & \underline{\text { SD }} & \underline{\mathbf{t}} \\ \text { Pretest } & \text { Lecture First } & 12.6 & 2.70 & \\ \text { Posttest } & \text { Lab First } & 11.6 & 3.58 & \\ & \text { Lecture First } & 18.6 & 3.34 & \\ & \text { Lab First } & 16.6 & 4.5 & 9.5^{*}\end{array}$

\section{Conclusion}

The implications of the results can lead to many future research questions. The results of the posttest indicate that it is better to lecture before having the students complete a laboratory experience. The results of the retention test indicate two things. First, there is no resulting significant difference over time between using an inquiry lab before or after a lecture on cognitive achievement as measured by the student teacher's instrument. Second, those that took part in the lecture/class discussion first, forgot more than those in the other group.

These results indicate that it is better to lecture before having the students do a hands-on experience when addressing the content in this unit in an urban high school in the southeast. Several confounding variables may potentially have caused these results. The students in the class that had the highest scores on the posttest and had a class discussion before the lab had higher class means than the other three classes on every test that had been previously administered during the year. Further research must be conducted in order to determine if there was an interaction between the respective classes and the teaching strategy. Another potential confounding variable was time of day. The two classes that had the class discussion first were later in the day than the two classes that conducted the lab first. Further research must be conducted in order to determine whether there was an interaction between the time of day and the teaching procedure.

A third area for further research involves the attitudes of the students. Perhaps they enjoyed discovering the material for themselves. This cannot be measured on a cognitive achievement test so future researchers could 
administer both an instrument that measures attitude and an instrument that measures achievement.

Attitude may have also played a part in the decreases in scores on the retention tests. The students knew that they were not going to be graded on their performance on the retention test, whereas they knew that they were going to be graded on the posttest. Therefore they may have just guessed on the retention test resulting in the dramatic decrease in scores.

Teaching procedures are sometimes dependent upon the content being covered. Clearly the students can learn content that might be addressed on a standardized test by doing an inquiry experiment. The recent experiment conducted by a student teacher indicates that a lecture or class discussion strategy should be carried out before a laboratory experience. While every teacher has their own strengths and every class has its own personality, we believe we have students who can learn content through inquiry and lab experiences as well as through lecture, and in our opinion, students can learn better through a good lab experience versus a lecture.

\section{References:}

Chang, C.Y. (1999). Comparison of Taiwan science students' outcomes with inquiry-group versus traditional instruction. Journal of Educational Research, 92 (6), 340-346. http://dx.doi.org/10.1080/00220679909597617

Dunn, Rita, et.al. (1995). A meta-analytic validation of the Dunn and Dunn Model of learning-style preferences. Journal of Educational Research. 88 (6), 353-362. http://dx.doi.org/10.1080/00220671.1995.9941181

Freedman, M.P. (1997). Relationships among laboratory instruction, attitude towards science, and achievement in science knowledge. Journal of Research in Science Teaching, 34 (4), 343-357. http://dx.doi.org/10.1002/(SICI)1098-2736(199704)34:4<343::AID TEA5>3.0.CO;2-R

Gega, P. C. \& Peters, J. M. (1998). Concepts and Experiences in Elementary School Science. $3^{\text {rd }}$ edition. Merrill Prentice Hall: Upper Saddle River, NJ. (10), 1121-1131. http://dx.doi.org/10.1002/tea.3660311006

Jones, V. S., Holland, A. J., \& Oldmeadow, W. (2008). Inductive teaching method-an alternate method for small group learning. Medical Teacher, 30(8), e246-249. doi: 10.1080/01421590802259274

Marshall, Jill A., \& Dorward, James T., (2000). Inquiry experiences as a lecture supplement for preservice elementary teachers and general education students. American Journal of Physics, 68 (7), S27-S35. http://dx.doi.org/10.1119/1.19516

Moore, R. (2008, January-February). Are Students' Performances in Labs Related to Their Performances in Lecture Portions of Introductory Science Courses? Journal of College Science Teaching, 66-70. 
National Research Council. (1996). National science education standards. Washington, DC: National Academy Press. http://www.nap.edu/ catalog.php?record_id=4962\#

Odubunmi, Olagunju, \& Balogun, T.A. (1991). The effect of laboratory and lecture teaching methods on cognitive achievement in integrated science. Journal of Research in Science Teaching, 28 (3), 213-224. http://dx.doi.org/10.1002/tea.3660280303

Saunders, W.L., \& Shepardson, D. (1987). A comparison of concrete and formal science instruction upon science achievement and reasoning ability of sixth grade students. Journal of Research in Science Teaching, 24 (1), 39-51. http://dx.doi.org/10.1002/tea.3660240105

Shymansky, J. A. (1984). BSCS programs: Just how effective were they? The American Biology Teacher, 46 (1), 54-57. http://www.jstor. org/stable/4447773

Shymansky, J.A., Kyle, W.C., Jr., \& Alport, J.M. (1982, NovemberDecember). How effective were the hands-on programs of yesterday? Science and Children, 14-15.

Staver, J.R., \& Pascarella, E.T. (1984). The effect of method and format on the responses of subjects to a Piagetian reasoning problem. Journal of Research in Science Teaching, 21 (3), 305-314. http://dx.doi.org/10.1002/tea.3660210307 